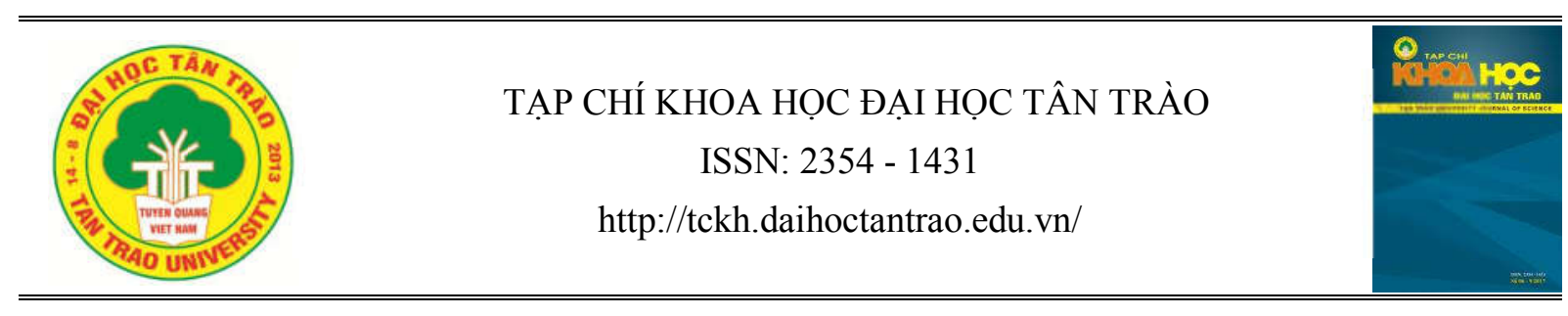

\title{
Tư tưởng Hồ Chí Minh về đồng chí, đồng nghiệp
}

\author{
Triệu Quang Minh ${ }^{a^{*}}$ \\ ${ }^{a}$ Học viện Chính trị Quốc gia Hồ Chí Minh khu vục I \\ *Email: minhhcm1@gmail.com
}

\section{Thông tin bài viết}

Ngày nhận bài:

22/01/2018

Ngày duyệt đăng:

$12 / 6 / 2018$

Tù khoá:

Đồng chi, đồng nghiệp, cán bộ.

\section{Tóm tắt}

Tư tưởng về đồng chí, đồng nghiệp không được hệ thống hoá thành một nội dung riêng biệt với những luận điểm cụ thể mà nằm trong sự giao thoa, song trùng với các tư tưởng khác. Bên cạnh đó, có thể thấy rằng trong mỗi lời nói, mỗi việc làm của Hồ Chí Minh đều bao chứa một bài học lớn mang ý nghĩa sâu sắc đối với cán bộ, đảng viên về cách đối nhân, xử thế giữa người với người nói chung và giữa đồng chí, đồng nghiệp với nhau nói riêng.
1. Xét về mặt ngữ nghĩa, "đồng chí" là khái niệm được tìm hiểu từ khía cạnh lập trường chính trị, dùng để chỉ những người cùng ý chí, cùng theo đuổi một mục đích, một lý tưởng hoặc cùng đứng trong một tổ chức cách mạng. Còn "đồng nghiệp" là khái niệm được nhắc tới trên phương diện công việc, dùng để chỉ những người cùng làm một công việc, cùng một nghề. Tuy vậy, trong tư tưởng của Hồ Chí Minh không có sự phân biệt tuyệt đối giữa đồng chí và đồng nghiệp mà hai khái niệm này được Người sử dụng trong sự giao thoa, thậm chí đôi khi là đồng nhất. Hồ Chí Minh đã xuất phát từ điều kiện lịch sử cụ thể của thực tiễn đất nước, từ tính chất đặc thù của cách mạng Việt Nam và nhận ra yêu cầu phải dựa trên khối đại đoàn kết toàn dân như một vũ khí chiến lược trong công cuộc bảo vệ và xây dựng đất nước. Trong cuộc cách mạng không ngừng của dân tộc, nhân dân cả nước không chỉ là đồng bào mà còn là đồng chí, đồng nghiệp của nhau cùng chiến đấu, đấu tranh và làm những công việc vì lợi ích chung của dân tộc. Hồ Chí Minh chỉ ra rằng, trong cuộc cách mạng lớn và lâu dài này, phương châm không phân biệt thành phần xuất thân, nghề nghiệp, giàu nghèo... sẽ đem lại sức mạnh đoàn kết để đánh thắng giặc ngoại xâm, giặc đói, giặc dốt. Cần phải xây dựng và duy trì khối đại đoàn kết toàn dân ấy trên cả hai mặt trận có tiếng súng và không tiếng súng với tinh thần "đoàn kết chặt chẽ, đoàn kết lâu dài, cùng nhau tiến bộ"1.

Trong quan niệm của mình, Hồ Chí Minh coi tất cả mọi người dù đứng trên cương vị và mặt trận nào cũng đều là đồng chí, đồng nghiệp của nhau. Đã là đồng chí, đồng nghiệp của nhau phải cùng san sẻ khó khăn, cùng giúp nhau tiến bộ, cùng phấn đấu vì mục tiêu chung... Đó chính là tư tưởng đạo đức thiết yếu của một người cách mệnh được Hồ Chí Minh nói tới trong tác phẩm “Euoòng kách mệnh". Người còn nhắc nhở một cách cụ thể:

"Với từng người thì khoan thứ

Với đoàn thể thì nghiêm

Có lòng bày vẽ cho người

Trực mà không táo bạo"²

Không chỉ dừng ở những nguyên lý chung mà trong mỗi lần đi sâu vào quần chúng, tiếp xúc với đồng bào, cán bộ, đảng viên Hồ Chí Minh luôn cụ thể hoá, đơn giản hoá, bình dân hoá lời căn dặn của mình để mọi người noi theo. Năm 1947, trong buổi làm việc với cán bộ tỉnh Thanh Hoá, Người chỉ rõ "Đối với đồng chí của minh phải thế nào?: Thân ái với nhau, nhưng không che đậy những điều dở. Học cái hay, sửa

${ }^{1}$ Hồ Chí Minh Toàn tập (2000), Nxb Chính trị quốc gia, Hà Nội, t.6 tr 184; ${ }^{2}$ Sđd tập 2, tr. 260; 
chữa cái dở. Không nên tranh giành ảnh hưởng của nhau. Không nên ghen ghét, đố kỵ và khinh kẻ không bằng mình. Bỏ lối hiếu danh, hiếu vị..."” . Theo Hồ Chí Minh, là đồng chí và đồng nghiệp của nhau phải đặt sự tương thân, tương ái lên hàng đầu, có vậy đoàn thể mới đoàn kết, nội bộ vững mạnh thì mới nói tới sự phát triển. Nhưng phải thận trọng, tỉnh táo trước mọi biểu hiện sai lầm của cán bộ, chẳng hạn "cánh hẩu" là biểu hiện của óc bè phái, phải ngăn chặn ngay. Tránh tình trạng xử lý công việc theo kiểu: “Ai hẩu với mình thì dù nói không đúng cũng nghe, tài không có cũng dùng. Ai không hẩu với mình thì dù có tài cũng dìm họ xuống, họ phải mấy cũng không nghe" ${ }^{4}$.

Hồ Chí Minh đã phân tích toàn diện tình hình chung và nhận thấy một thực tế là: "Có những đồng chí còn giữ óc địa vị cố tranh cho được uỷ viên này, chủ tịch kia. Có những đồng chí lo ăn ngon, mặc đẹp, lo chiếm của công làm của tư, lợi dụng địa vị và công tác của mình mà buôn bán phát tài, lo việc riêng hơn việc công... Có những đồng chí còn giữ thói "một người làm quan cả họ được nhờ, đem bà con, bạn hữu đặt vào chức này, việc kia, làm được hay không mặc kệ. Hỏng việc đoàn thể chịu, cốt cho bà con, bạn hữu có điạ vị là được" $"$. Lo lắng về vấn đề này, Hồ Chí Minh luôn nhắc nhở làm cán bộ đối với đồng chí, đồng nghiệp của mình phải đem những ưu điểm tốt mà kiên quyết khắc phục những khuyết điểm vừa kể trên.

Là đồng chí, đồng nghiệp phải rộng lượng, phải nhìn vào mặt tốt để cất nhắc họ, phải bỏ qua lỗi lầm nhỏ để động viên họ cố gắng, không được vì sợ thua thiệt mà không trọng người tài hơn mình. Hồ Chí Minh cho rằng: "Người đời ai cũng có chỗ hay, chỗ dở. Ta phải dùng chỗ hay của người và giúp người chữa chỗ dở. Dùng người cũng như dùng gỗ. Người thợ khéo thì gỗ to, nhỏ, thẳng, cong đều tuỳ chỗ mà

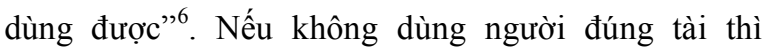
không những không phát huy được khả năng của họ mà có khi còn hỏng việc, hại đến tập thể. Cũng giống như "thợ rèn thì bảo đi đóng tủ, thợ mộc thì bảo đi rèn dao. Thành thử cả hai người đều lúng túng""7 Làm cán bộ, đặc biệt là cán bộ giữ chức vụ lãnh đạo phải biết đặt lợi ích tập thể lên trên lợi ích cá nhân và hơn hết phải cùng khổ, cùng vui với đồng chí, anh em của

\footnotetext{
${ }^{3}$ Sđd, tập 5, tr. 54;

${ }^{4}$ Sđd, tập 5, tr. 72;

${ }^{5}$ Sđd, tập 5, tr.74.

${ }^{6}$ Sđd, tập 5, tr.72;

${ }^{7}$ Sđd, tập 5, tr.274;
}

mình. Điều này được Người một lần nữa nhắc lại trong lời căn dặn các chiến sỹ công an. Theo Người, đối với đồng sự phải thân ái giúp đỡ, là đồng chí thì phải yêu thương lẫn nhau nhưng không được vì thế mà che giấu khuyết điểm của nhau: "Nhiều nơi các đồng chí phạm lỗi nhưng không bị trừng phạt xứng đáng, có đồng chí bị hạ tầng công tác ở nơi này, đi nơi khác lại ở nguyên cấp cũ hay chỉ bị hạ tầng công tác theo hình thức, nhưng vẫn ở cấp bộ cũ làm việc. Có đồng chí đáng phải trừng phạt, nhưng vì tình cảm nể nang, chỉ phê bình cảnh cáo qua loa cho xong chuyện. Thậm chí còn có nơi che đậy cho nhau, tha thứ lẫn nhau, lừa dối cấp trên, giấu giếm đoàn thể," 8 .

Hồ Chí Minh luôn nhấn mạnh công tác phê bình và tự phê bình. Mục đích của phê bình cốt để giúp nhau sửa chữa, giúp nhau tiến bộ; cốt để sửa chữa cách làm việc cho tốt hơn, đúng hơn; cốt đoàn kết và thống nhất nội bộ. Vì vậy, tự phê bình bình cũng nhu phê bình phải ráo riết, triệt để, thật thà, không nể nang, không thêm bớt. Phải chỉ rõ cả ưu điểm và khuyết điểm. Đồng thời, chớ dùng những lời mỉa mai, chua cay, đâm thọc. Những người bị phê bình thì phải vui lòng nhận xét để sửa đổi, không nên vì bị phê bình mà nản chí hoặc oán ghét. Theo Người: "Mục đích phê bình và tự phê bình là để cho mình tiến bộ, quân đội và nhân dân tiến bộ, để tăng thêm tình đoàn kết giữa cán bộ với cán bộ, giữa cán bộ với chiến sỹ, giữa quân đội với nhân dân" "9. Tự phê bình phải thật thà ví nhu người ốm yếu nói rõ bệnh tình của mình cho thầy thuốc. Thấy mình có nhiều bệnh, sợ không sửa chữa được mà bi quan, tiêu cực là không đúng. Mình không sửa chữa được đã có đồng chí, nhân dân bày cách cho mà sửa chữa. Phê bình đồng chí, đồng nghiệp cũng phải có cách, sao cho khéo vì “ai cũng có khuyết điểm nhưng ai cũng có ưu điểm... Nói cái xấu phải nói cả cái tốt. Nếu chỉ chuyên nói cái xấu là lệch" ${ }^{10}$.

2. Tiếp cận tư tưởng Hồ Chí Minh về đồng chí, đồng nghiệp để xây dựng thành hệ chuẩn mang tính giáo dục cho mỗi cán bộ là một trong những biện pháp để nâng cao phẩm chất đạo đức cách mạng cho cán bộ và xây dựng một tập thể chung vững mạnh từ bên trong. Sống và làm việc theo gương của Bác Hồ, vận dụng tư tưởng của Người vào việc ứng xử với đồng chí, đồng nghiệp của mình, mỗi cán bộ cần cố gắng rèn luyện cho mình lối sống, tác phong làm việc giản

\footnotetext{
${ }^{8}$ Sđd, tập 5, tr.73;

${ }^{9}$ Sdd, t. 6 tr. 322 ;

${ }^{10}$ Sđd, tập 6, tr.322.
} 
dị nhưng khoa học, hiệu quả dựa trên nguyên tắc tập trung dân chủ và mỗi người chúng ta cần lưu ý những yêu cầu sau: thứ nhất, trong công việc, cần phải có thái độ cầu thị, cầu tiến bộ, phải lắng nghe ý kiến của những cán bộ khác. Không được dùng ý kiến, quan điểm mang tính chất chủ quan của mình để quyết đáp các công việc của tập thể; Thứ hai, phải tôn trọng đồng chí, đồng nghiệp mình trong mọi công việc được giao; Thứ ba, làm người ai cũng có ưu điểm và nhược điểm, cho nên đối với đồng chí của mình phải biết tạo cơ hội cho họ phát huy ưu điểm đồng thời khéo léo chỉ cho họ những nhược điểm để khắc phục.

Theo Hồ Chí Minh, nếu là cán bộ lãnh đạo phải tạo cơ hội cho các cán bộ cấp dưới của mình phấn đấu. Không được vì tư lợi, vì thân quen mà cất nhắc cán bộ vì như thế là hại cho tổ chức, hại cho cả bản thân người được cất nhắc. Dùng người phải tuỳ người, tuỳ tài, tuỳ hoàn cảnh cụ thể. Phải "có gan cất nhắc" và chú ý bồi dưỡng cán bộ. Tránh "rụt rè", "quá khe khắt", cũng như tránh "vội vàng", thiếu thận trọng lúc cất nhắc. "Cất nhắc cán bộ, không nên làm như "giã gạo". Nghĩa là, trước khi cất nhắc không xem xét kỹ, khi cất nhắc rồi không giúp đỡ họ. Khi họ sai lầm thì đẩy xuống. Chờ lúc họ làm khá lại cất nhắc lên" ${ }^{\prime 1}$. Vì theo Người, một cán bộ bị nhấc lên, thả xuống ba lần như thế là hỏng cả đời. Đồng chí của mình mà có tài không sợ bạn hơn mình, bạn không bằng mình phải giúp bạn cùng tiến bộ. Tránh tình trạng vì không được cất nhắc mà không ủng hộ lãnh đạo hoặc trước mặt thì ủng hộ, sau lưng lại làm trái, nói xấu cấp trên... Nghĩa là, giỏi không kiêu ngạo, không khinh kẻ không bằng mình, kém không đố kỵ, không ghét kẻ hơn mình, tránh mọi thiên hướng của sự thái quá, lệch lạc, siêu hình nhờ việc xét đoán toàn diện các mặt của vấn đề. Như vậy, trong công việc mỗi cán bộ, đảng viên cần học tập và làm việc theo phong cách Hồ Chí Minh. Có thể diễn đạt phong cách đó trên bốn phương diện co bản sau đây:

Một là, tạo cho mình tác phong quần chúng tức là phải chú ý tìm hiểu tâm tư, nguyện vọng cũng như những thuận lợi, khó khăn của đồng chí, đồng nghiệp mình; Tôn trọng và lắng nghe những ý kiến góp ý, phê bình của đồng chí, đồng nghiệp và phát huy ưu điểm cũng như sửa chữa những khuyết điểm của mình; Đẩy mạnh công tác phê bình và tự phê bình trong tổ chức, đơn vi .
Hai là, tạo cho mình thói quen xử lý công việc dựa trên nguyên tắc tập thể - dân chủ. Nghĩa là, phải ủng hộ phong trào chung, gắn bó quyền lợi của mình với tập thể, tôn trọng tập thể; Lắng nghe mọi ý kiến, không phân biệt chức vụ, cấp bậc cao hay thấp.

Ba là, tạo cho mình tác phong làm việc khoa học. Tức là, cần suy xét kỹ, lập chương trình, kế hoạch giải quyết, kiểm tra, đối chiếu, đánh giá lại kết quả một cách khách quan, toàn diện.

Bốn là, trang bị cho mình phương pháp tư duy biện chứng. Phương pháp ấy sẽ định hướng cho mỗi cán bộ, đảng viên trong hành động, tránh được mọi thiên hướng của sự thái quá, lệch lạc, siêu hình nhờ việc xét đoán toàn diện các mặt của vấn đề.

Hiện nay, đất nước ta đang ở vào thời kỳ đẩy mạnh công nghiệp hoá, hiện đại hoá với nhiều thời cơ và thách thức lớn. Điều kiện mới đòi hỏi phải nâng cao hơn nữa chất lượng đội ngũ cán bộ, đảng viên. Muốn thế, mỗi người cán bộ, đảng viên phải thấm nhuần hơn nữa đạo đức Hồ Chí Minh. Do đó, giáo dục đạo đức của Hồ Chí Minh cho đội ngũ cán bộ, đảng viên đang tiếp tục trở thành một trong những vấn đề cấp bách nhất hiện nay khi mà sự suy thoái đạo đức đang trở thành căn bệnh mãn tính cần liều thuốc kháng sinh cực mạnh. Khi mà chủ nghĩa cá nhân đang sống lại và gây ra những ảnh hưởng trực tiếp... làm cho xã hội có phần bất ổn, nội bộ một số tập thể mất đoàn kêt, không ít các cá nhân có năng lực không được trọng dụng và không có cơ hội cống hiến. Giải quyết được tận gốc rễ của vấn đề này đòi hỏi có sự chuẩn bị kỹ càng, cũng như sự phối hợp triệt để, liên tục và lâu dài của tất cả các ban, ngành nhưng quan trọng nhất vẫn là tinh thần tự giác của mỗi cán bộ, đảng viên. Bởi lẽ, biến quá trình giáo dục thành quá trình tự giáo dục bao giờ cũng đem lại hiệu quả cao nhất và lâu dài nhất. Muốn vậy, trước tiên, phải bắt đầu xuất phát từ việc đẩy mạnh quy mô, phương thức vận dụng tư tưởng Hồ Chí Minh về đồng chí, đồng nghiệp để giáo dục đạo đức cho cán bộ. Đây là một trong những biện pháp để nâng cao phẩm chất đạo đức của đội ngũ cán bộ, đảng viên trong giai đoạn hiện nay, làm cho mỗi lời dạy của Người thấm vào suy nghĩ và thể hiện ra qua hành động của họ. Theo đó, mỗi cán bộ, đảng viên cần vận dụng chính xác, linh hoạt lời căn dặn của Người trong

${ }^{11}$ Sđd, tập 5, tr.282. 
quan hệ, ứng xử với đồng chí, đồng nghiệp của mình; phải tự giác tạo lập cho mình thói quen làm theo phương pháp và phong cách Hồ Chí Minh. Trong Văn kiện Đại hội lần thứ XII, Đảng ta nhấn mạnh: "Tiếp tục đẩy mạnh việc học tập và làm theo tư tưởng, phong cách Hồ Chí Minh... Xây dựng và thực hiện tốt các quy định để phát huy vai trò gương mẫu trong rèn luyện phẩm chất, đạo đức, lối sống, phong cách, tác phong, lề lối công tác của cán bộ, đảng viên, nhất là cán bộ lãnh đạo các cấp, người đứng đầu các cơ quan đơn vị ${ }^{12}$.

\section{TÀI LIẸU THAM KHẢO}

1. Đảng Cộng sản Việt Nam (2016), Văn kiện Đại hội Đại biêu toàn quốc lần thứ XII, Văn phòng Trung ương Đảng, Hà Nội;

2. Hồ Chí Minh Toàn tập(2000), Nxb Chính trị quốc gia, Hà Nội, tập 2, 5, 6.

\section{Ho Chi Minh's ideology of comrades and colleagues}

Trieu Quang Minh

\section{Article info}

Recieved:

22/01/2018

Accepted:

$12 / 6 / 2018$

Keywords:

Comrades, colleagues,

officials...

\section{Abstract}

In Ho Chi Minh's ideologies, the ideology of comrades and colleagues is not systematized into a separate content with specific points, but it is included in the interference and parallel with other ideologies. In addition, we can see that, in Ho Chi Minh any words and every matters always consists of great and meaningful lessons with profound meanings for officials and Party members on how to behave among people in general and among comrades, colleagues in particular.

${ }^{12}$ Đảng Cộng sản Việt Nam (2016), Văn kiện Đại hội Đại biểu toàn quốc lần thứ XII, Văn phòng Trung ương Đảng, Hà Nội, tr.202-203. 